\title{
Health as a Complete State: The Added Value in Work Performance and Healthcare Costs
}

\author{
Corey L. M. Keyes \\ Joseph G. Grzywacz
}

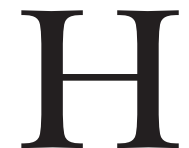

Objective: Health is widely believed to be more than the absence of illness, yet no previous research has documented whether organizations would benefit if occupational health moved beyond an "absence of illness" model. Methods: Cross-sectional data from the Midlife Development in the United States (MIDUS) study were used to compare productivity outcomes and health care use among individuals in (1) complete ill health, (2) incomplete health, and (3) complete health. Results: Across the outcomes, individuals characterized as being completely healthy reported the greatest productivity and the lowest health care use. By contrast individuals in incomplete health had intermediate levels on outcomes and individuals in complete ill-health had the poorest outcomes. Conclusion: There is additional benefit of moving occupational health priorities from health as the absence of illness to health as more than the absence of illness. (J Occup Environ Med. 2005;47: 523-532)
From the Department of Sociology, Emory University, Atlanta, Georgia (Dr Keyes); Department of Behavioral Sciences and Health Education, The Rollins School of Public Health, Atlanta, Georgia (Dr Keyes); and Department of Family and Community Medicine, Wake Forest University School of Medicine, Medical Center Boulevard, Winston-Salem, North Carolina (Dr Grzywacz).

Supported by the John D. and Catherine T. MacArthur Foundation Research Network on Successful Midlife Development (Dr Orville Gilbert Brim, Director).

Address correspondence to: Corey L. M. Keyes, Department of Sociology, Room 225 Tarbutton Hall, Emory University, 1555 Dickey Drive, Atlanta, GA 30322; E-mail: corey.keyes@emory.edu. Copyright $(\odot$ by American College of Occupational and Environmental Medicine

DOI: 10.1097/01.jom.0000161737.21198.3a ealth has been valued as one of the highest goods in life that permits individuals, organizations, and society to thrive. ${ }^{1}$ In the absence of health, the Greeks believed that wealth, wisdom, and aptitude could not be fully realized, implemented, or enjoyed. Consistent with recent calls from occupational health scholars, ${ }^{2}$ physical health and mental health are considered important forms of "human capital" that are clearly linked to the economic performance of organizations and development of nations. ${ }^{3,4}$ Recognizing that health is the engine of national growth, the Surgeon General mandated that the mission of Public Health is "to protect and improve American health" [our emphasis added.$^{5}$

Despite proclamations to value health, morbidity and mortality are what count and get counted in health professions, including occupational health. Health promotion advocates have long argued the virtues of illness reduction for reducing health care costs and enhancing individuals' ability to perform their occupational, institutional, and social responsibilities. $^{6,7}$ Although health researchers and practitioners argue that organizations and communities can benefit by promoting individual health, they test their ideas by modeling how the reduction of disease or disease potential can lessen costs associated with illness. ${ }^{8-10}$ It appears clear that health-promotion programs that identify levels of risk among individuals and that implement interventions to reduce health risks in worker populations provide mean- 
ingful returns on investment. ${ }^{8,11-16}$ Thus far, the mission of public health activity, including occupational health, consists of actions to reduce pathogenic conditions and behaviors that protect against death and disease. With this approach, healthimprovement programs can only achieve a partial version of health as the relative absence of disease and illness. The question remains whether there are compelling reasons to strive for more than the absence of illness or disease?

We agree that health is an important form of human capital that provides competitive advantage to organizations, ${ }^{17}$ but we believe occupational health researchers need to consider the absence of illness and injury along with the presence of well-being. For years, health has been alleged to be a complete state consisting of not merely the absence of physical or mental illness but also the presence of "something positive." 1,18 The conceptual model that health promotion is built upon as well as empirical evidence indicates that health is more than the absence of illness. ${ }^{19-22}$ However, health as the presence of something positive does not get counted (ie, measured), and therefore does not yet count, in the United States. If it were, health practitioners would create programs and policies that both protect (ie, maintain) extant health or improve its absence by increasing salutogenic (Salus is Latin for "health") and fortigenic (Fortis is Latin for "strength," and genic is Greek for "causes of") conditions and behaviors. ${ }^{23}$

Besides the study of comorbidity of specific illnesses within brief periods, ${ }^{24}$ health and its impacts are studied separately and piecemeal. This compartmentalization of health stems from skepticism about the basic and applied value of the study of health as a complete state that includes "something positive." Health viewed as more than the absence of disease is seen as an idealized, unattainable concept that is useful for inspirational declarations but not pragmatic for research and health objectives. For example, and in the domain of mental health, Mechanic ${ }^{25}$ declares without supporting evidence that, "Although the concept of positive mental health is one worth keeping in mind, it is not very helpful in classifying different persons, groups, or populations" (p. 2). Moreover, the World Health Organization's definition of health as a complete state is routinely dismissed as impractical, considered overly inclusive of human activities, and believed to be too difficult and cumbersome for population health measurement. ${ }^{26-28}$

However, a new empirical standard is needed to evaluate health programs across different settings and to measure and promote progress on protecting and improving occupational health. Many countries like the United States have undergone the epidemiological transition in the causes of disease and death. The compression of morbidity envisioned by Fries ${ }^{29}$ and the vision of health for all people as initiated by the Declaration of Alma $\mathrm{Ata}^{30}$ remain unrealized. $^{31}$ The continued focus on diseases and risk factors that contribute to the leading causes of death and morbidity has ironically increased the number of years spent living and working with disability (ie, unhealthy). ${ }^{32}$ Although many developed nations spend much money per capita on health, rates of health problems normally associated with increased age-for example, depression, obesity, and diabetes-are not only rising in the overall population but also occurring at younger ages. ${ }^{33}$ Third, healthcare in countries such as the United States has become one of the most costly budget items for families, businesses, and government, consuming almost one-seventh (ie, approximately 14\%) of the Gross Domestic Product (GDP). By approxiately 2020, as the baby boom generation begins to reach the age of about 70, healthcare costs are projected to increase to approximately one-quarter of the GDP. ${ }^{34}$ Although nations can continue to aspire to increase life expectancy and decrease morbidity, achieving these goals will be more difficult, more costly, and will be valued by citizens only if those added years are accompanied by a sense of well-being and significance. $^{35}$

Complete health, defined as the absence of physical and mental morbidity and the presence of physical and mental well-being, can be measured and evaluated. ${ }^{19}$ The strategy for measuring complete health draws on tools from a variety of disciplines focused on health, and it creates three main groups characterized by differential clusters of indicators of morbidity and well-being. Complete health is the absence of physical and mental morbidity and the presence of sufficient levels of physical and mental well-being; incomplete health reflects either high levels of physical health and well-being but poor mental health (high morbidity or low well-being) or high levels of mental health and well-being but poor physical health (high morbidity or low well-being); and completely unhealthy (high physical and mental morbidity and low physical and mental well-being).

This conceptualization and measurement strategy have been used in recent studies that document prevalence and distribution ${ }^{19}$ and some social and behavioral antecedents ${ }^{36}$ of the categories of complete health. Findings show that $19 \%$ of US adults were completely healthy, $19 \%$ were completely unhealthy, whereas $62 \%$ had incomplete health, of which $52 \%$ were physically unhealthy but mentally healthy and 10\% were physically healthy but mentally unhealthy. In turn, behavioral risk factors typically targeted in health-promotion programs were associated with increased odds of being completely healthy (eg, regular physical activity), whereas other salient diseaseprevention targets such as smoking and its cessation did not differentiate completely healthy individuals from incompletely healthy individuals. ${ }^{36}$ Moreover, behaviors indicative of 
greater social capital and integration (eg, religious attendance) were equally strong correlates of complete health as personal health behaviors such as exercise.

Although complete health can be evaluated and monitored, there are no studies that document whether striving for complete health provides added tangible value to those who pay for health programs. The basic question asked in this paper is the following: If individual health is more than the absence of illness, is there added value to public and occupational health for heeding admonishments to move beyond disease prevention toward health promotion? $?^{22,37}$ As such, this study investigates differences in individual indicators of work-related productivity and health care utilization by complete health status. We hypothesize that work-related productivity is highest and health care costs are lowest among individuals who are completely healthy; anything less than complete health should be associated with reductions in workrelated productivity and increments in health care costs.

\section{Materials and Methods}

\section{Sample}

Data are from the Midlife in the United States (MIDUS) survey conducted by the MacArthur Foundation's Research Network on Successful Midlife Development. MIDUS is a national probability sample, drawn with random-digit dialing procedures, consisting of English-speaking, noninstitutionalized adults, aged 25 to 74 , residing in the 48 contiguous states, and whose household includes at least one telephone. The first stage of the multistage sampling design selected households with equal probability via telephone numbers. Disproportionate stratified sampling was used at the second stage to select respondents. The sample was stratified by age and gender, with oversampling of men between the ages of 65 and
74. Working but nonhousehold numbers (eg, business) were eliminated by definition. Working numbers that were unsuccessfully contacted 10 times also were eliminated.

Adults who agreed to participate were administered a computerassisted telephone interview lasting 45 minutes on average and were then mailed two questionnaire booklets requiring approximately 1.5 hours on average to complete. All participants were offered $\$ 20$ and a copy of a final study monograph as incentives for participation. With a response rate of $70 \%$ for the telephone phase and a response rate of $87 \%$ for the self-administered questionnaire phase, the overall response rate was $61 \%$, with a sample size of 3032 respondents. Field procedures lasted approximately 13 months in 1994 to 1995.

All descriptive analyses present the findings based on the weighted sample. The sampling design involved some complexities that could introduce design effects that inflate standard error estimates. However, simulations using jackknife repeated replications $^{38}$ on an array of variables revealed very small standard error inflation of design-based estimates, eliminating the need to adjust statistical tests for design effects in these data.

\section{Measures}

Complete health, the primary independent variable in this study, is a measure that is constructed from several indicators of physical and mental illness as well as indicators of physical and mental well-being. In this section, we first describe the measurement attributes of each component of complete health, and then we detail how these measures are combined to categorize individual health status.

Mental Illness. The MIDUS uses the structured DSM-III- ${ }^{39}$ to diagnose mental illness. The MIDUS uses the Composite International Diagnostic Interview Short Form (CIDI-SF) scales, ${ }^{40}$ which has shown excellent diagnostic sensitivity and specificity, as compared with diagnoses based on the complete CIDI in the National Comorbidity Study. ${ }^{40}$ During the telephone interview, the CIDI-SF was used to assess whether respondents exhibited symptoms indicative of 1) major depression episode, 2) generalized anxiety disorder, and 3) panic disorder during the past 12 months.

Mental Health. By self-administered questionnaire, respondents indicated how much of the time during the past 30 days-"all," "most," "some," "a little," or "none of the time"-they felt six symptoms of positive affect. The positive affect symptoms are 1) cheerful, 2) in good spirits, 3) extremely happy, 4) calm and peaceful, 5) satisfied, and 6) full of life. The internal reliability of the positive affect scale is 0.91 . Moreover, respondents were asked to "rate their life overall these days" on a scale from 0 to 10 , where 0 meant the "worst possible life overall" and 10 meant "the best possible life overall."

Ryff 's ${ }^{41}$ measures of six dimensions of psychological well-being operationalize how much individuals see themselves thriving in their personal life. The scales represent distinctive dimensions ${ }^{42}$ of subjective well-being. The scales with a representative item in parenthesis are as follows: self-acceptance ("I like most parts of my personality"), positive relations with others ("maintaining close relationships has been difficult and frustrating for me"), personal growth ("For me, life has been a continual process of learning, changing, and growth"), purpose in life ("I sometimes feel as if I've done all there is to do in life"), environmental mastery ("I am good at managing the responsibilities of daily life"), and autonomy ("I tend to be influenced by people with strong opinions").

Keyes' ${ }^{43}$ measures of social wellbeing operationalize how much individuals see themselves thriving in their social life. The scales with a 
representative item in parentheses are as follows: social-acceptance ("People do not care about other peoples' problems"), social actualization ("Society isn't improving for people like me"), social contribution ("My daily activities do not create anything worthwhile for my community"), social coherence ("I cannot make sense of what's going on in the world"), and social integration ("I feel close to other people in my community").

All of the psychological and social well-being scales consisted of three items with a relative balance of positive and negative items and were self-administered. On a scale from 1 to 7 (with 4 as a middle category of neither agree nor disagree), respondents indicated whether they agreed or disagreed strongly, moderately, or slightly that an item described how they functioned (ie, thought or felt). Negative items were reverse-coded. The three-item scales of psychological well-being have shown modest internal consistency, ${ }^{42}$ and the internal consistency of the combined 18 items is 0.81 . The three-item scales of social well-being have shown modest-to-excellent internal consistency, ${ }^{43}$ and the internal consistency of the combined items is 0.81 .

To diagnose mental health, the well-being scales were divided by the number of constituent items, then standardized, and tertiles were computed. Individuals with scores in the upper tertiles of one of the two emotional well-being scales and 6 of the 11 scales of psychological and social well-being were classified as flourishing. Individuals with scores in the lower tertiles of one of the two emotional well-being scales and 6 of the 11 scales of psychological and social well-being were classified as languishing. Adults who were neither flourishing nor languishing were classified as moderately mentally healthy. ${ }^{22}$

Physical Illness. To identify the absence of morbidity, we used an inventory of common chronic conditions developed for the MIDUS and an index of functional impairments adapted from the Medical Outcomes Study. Specifically, respondents were asked in the selfadministered questionnaire, "In the past 12 months, have you experienced or been treated for any of the following. . ," and then given a list of 29 common chronic conditions (eg, asthma, arthritis, high blood pressure) to which they could answer yes or no. Respondents were then asked to indicate if their health limited their involvement in six basic or instrumental activities of daily living, including: 1) lifting or carrying groceries; 2) bathing or dressing; 3) climbing several flights of stairs; 4) bending, kneeling, or stooping; 5) walking several blocks; and 6) walking one block. Response categories for the functional limitation items were $1=$ "a lot," 2 = "some," 3 = "a little," and $4=$ "not at all" $(\alpha=0.85)$.

Physical Health. Two single-item questions were used to identify the presence of physical well-being, or the subjective experience of physical health. The first was "Using a scale from 0 to 10 where 0 means 'the worst possible health' and 10 means 'the best possible health,' how would you rate your health these days?" The second item asked, "How would you rate yourself today compared to five years ago on.... Energy level?" The response categories for the second item was 1 = "better now," 2 = "no change," and $3=$ "worse now."

Complete Health. The construction of complete-health proceeded in two steps. First, a categorical measure of optimal health was constructed for both mental and physical health. The three categories of optimal mental health included: 1) individuals classified as either moderately mentally healthy or flourishing and did not meet criteria for any of the assessed psychiatric morbidities; 2) individuals classified as "languishing" but not meeting criteria for psychiatric morbidity, or being classified either moderately mentally health or flourishing but also meet- ing criteria for psychiatric morbidity; and 3) individuals classified as languishing and who met criteria for psychiatric morbidity. Optimal physical health was operationalized dichotomously by assigning a value of 1 to individuals who reported all of the following: 1) one or fewer chronic conditions, 2) one or fewer functional limitations, 3) selfassessed health status greater than or equal to 7 (ie, in the top quartile), and 4) the "same" or "better" energy level now than 5 years previously. Respondents with more than one chronic condition or functional limitation, a self-assessed level of health of 6 or less, and whose energy level over the last 5 years was "worse" were coded zero.

At the second step, complete health was constructed by crossclassifying optimal mental and physical health creating several mutually exclusive categories, including 1) complete health (low/no physical morbidity and high physical wellbeing, coupled with low/no mental morbidity and high mental wellbeing), 2) complete ill health (high physical morbidity and low physical well-being coupled with high mental morbidity and low mental wellbeing), and 3) incomplete health. To be consistent with the original operationalization of complete health, four categories of incomplete health were specified: 1) physically healthy but mentally unhealthy, 2) physically unhealthy but mentally healthy, 3) partly physically healthy but mentally unhealthy, and 4) partly physically healthy but mentally healthy.

Outcome Variables. Work-related productivity is operationalized through self-reported thought/effort put into work, number of work cutback days, and the number of work loss days. Respondents were asked to indicate the amount of thought and effort they put into their paid work these days, on a scale from 0 to 10 , where 0 meant "none" and 10 meant "very much." Respondents also indicated the number of workdays lost and workdays cut back during the 
TABLE 1

Unadjusted Association of Measures of Work-Related Performance with Complete Health (Sample Weighted)

\begin{tabular}{|c|c|c|c|c|}
\hline & $\begin{array}{l}\text { Completely Unhealthy } \\
n=567(18.8 \%)\end{array}$ & $\begin{array}{l}\text { Incomplete Health } \\
n=1878(62.2 \%)\end{array}$ & $\begin{array}{l}\text { Completely Healthy } \\
n=574(19.0 \%)\end{array}$ & $\begin{array}{c}\text { Mean or Total } \\
\%\end{array}$ \\
\hline Low (bottom quartile) work effort & $31.7 \%$ & $18.6 \%$ & $8.9 \%$ & $19.2 \%$ \\
\hline $\begin{array}{l}\text { Mean work cutbacks past } 30 \text { days: those } \\
\text { with any cutbacks }\end{array}$ & 8.0 & 4.8 & 3.0 & 5.9 \\
\hline Any workdays lost past 30 days & $36.7 \%$ & $14.5 \%$ & $8.2 \%$ & $17.5 \%$ \\
\hline
\end{tabular}

All $P$ values $<0.001$ (two-tailed).

past 30 days. Specifically, of the past 30 days, respondents were asked, "how many days were you totally unable to go to work or carry out your normal household work activities because of your physical health or mental health?" Subsequently, of the past 30 days, and aside from those days they were totally unable to work, respondents were asked, "how many of the other days did you have to cut back on work or how much you got done because of your physical health or mental health?"

Health care costs were measured via medical visits, work injuries, hospitalization, and prescription medication use. Medical visits are a combined measure of the number of physical health and mental health medical visits during the past 12 months. Physical health medical visits were measured by asking respondents the number of visits during the past 12 months for reason of their own physical health. The visits included seeing doctor, hospital, or clinic for a routine physical check-up or gynecological examination; a dentist or optician for a routine check-up or examination; a doctor, emergency room, or clinic for urgent care treatment; or a doctor, hospital, clinic, orthodontist, or ophthalmologist for scheduled treatment or surgery. Mental health medical visits were measured by asking respondents the number of times they had seen a psychiatrist, general practitioner, or other medical doctor or a psychologist, professional counselor, mar- riage therapist, or social worker during the past 12 month for their personal problems (eg, alcohol, stress, relationship) or with their own emotional, mental health.

Work injury was measured by asking respondent how many times in the past 5 years had they suffered an accident or injury at a place they worked. Hospitalization was measured by asking respondents how many separate times in the past 12 months they had been hospitalized overnight. Last, respondents were asked is they had taken prescription medicine during the past 30 days for several conditions. The medical conditions were listed as follows: hypertension or high blood pressure, diabetes, high cholesterol, a heart condition, lung problems, ulcers, arthritis, hormone replacement or menopause, birth control, headaches, and "nerves," anxiety, or depression.

Control Variables. Age, gender, minority ethnic status, marital status, employment status, educational attainment, and total household earnings were controlled for in all multivariate analyses.

\section{Results}

Table 1 presents the unadjusted associations of measures of workrelated productivity with the complete health categories. As predicted, completely healthy adults had higher levels of work-related productivity than adults with incomplete health, who in turn reported better workrelated productivity than completely unhealthy adults, who had markedly low levels of work-related productivity.* The amount of self-reported thought and effort put into work was slightly higher among adults with complete health than adults with incomplete health, while adults with complete ill-health reported and average of one point less work effort than adults with incomplete health. Because the distribution was skewed toward the upper limit of the work effort scale, we then looked at the bottom quartile of the work effort measure (ie, scale score of a 6 or less). Almost one-third of completely unhealthy adults reported work effort in the bottom quartile, compared with just more than $18 \%$ of adults with incomplete health and 9\% of adults with complete health.

Nearly $42 \%$ of completely unhealthy adults reported a work cutback of more than $50 \%$ of the day compared with $18 \%$ of adults with incomplete health and only $8 \%$ of adults with complete health. Even among adults who had any work cutbacks, completely unhealthy adults cutback an average of 8 days, whereas adults with incomplete health cutback an average of 5 days, and completely healthy adults who had cutbacks did so an average of only 3 days. Nearly $38 \%$ of com-

\footnotetext{
*We did not restrict our analyses to those individuals who were currently employed because individuals who are unattached to the labor force frequently have substantial workrelated responsibilities for family or community.
} 


\section{TABLE 2}

OLS and Simple Logistic Regressions of Work-Related Performance Measures onto Complete Health Status (Sample Unweighted)

\begin{tabular}{|c|c|c|c|c|c|c|c|c|c|c|}
\hline \multirow[b]{2}{*}{ Predictor } & \multicolumn{2}{|c|}{ Work Effort } & \multicolumn{2}{|c|}{$\begin{array}{l}\text { Any Workday } \\
\text { Cutbacks }\end{array}$} & \multicolumn{2}{|c|}{$\begin{array}{c}\text { Work } \\
\text { Cutbacks: } \\
\text { Those With Any }\end{array}$} & \multicolumn{2}{|c|}{$\begin{array}{l}\text { Any Workday } \\
\text { Lost }\end{array}$} & \multicolumn{2}{|c|}{$\begin{array}{c}\text { Workdays } \\
\text { Lost: } \\
\text { Those With Any }\end{array}$} \\
\hline & b & $\boldsymbol{\beta}$ & OR & (95\% Cl) & b & $\boldsymbol{\beta}$ & OR & (95\% Cl) & b & $\boldsymbol{\beta}$ \\
\hline Completely healthy & - & - & 1.0 & $(-)$ & - & - & 1.0 & $(-)$ & - & - \\
\hline Incomplete health & $-0.53^{\star \star \star}$ & -0.11 & $2.6^{\star \star \star}$ & $(1.9-3.7)$ & 1.7 & 0.12 & $2.0^{\star \star \star}$ & $(1.4-2.7)$ & 0.36 & 0.04 \\
\hline Completely unhealthy & $-1.2^{\star \star \star}$ & -0.19 & $8.6^{\star \star \star}$ & $(6.0-12.5)$ & $4.2^{\star \star \star}$ & 0.30 & $6.0^{\star \star \star}$ & $(4.2-8.7)$ & $2.2^{\star \star \star}$ & 0.21 \\
\hline \multicolumn{11}{|l|}{ Control variables } \\
\hline Males & - & - & 1.0 & $(-)$ & - & - & 1.0 & $(-)$ & - & - \\
\hline Females & $0.29^{\star \star \star}$ & 0.08 & $1.8^{\star \star \star}$ & $(1.5-2.2)$ & 0.29 & 0.04 & $1.5^{\star \star \star}$ & $(1.2-1.8)$ & 0.06 & 0.01 \\
\hline Non-Hispanic Whites & - & - & 1.0 & $(-)$ & - & - & 1.0 & $(-)$ & - & - \\
\hline Minority Status & -0.07 & -0.01 & 1.1 & $(0.84-1.1)$ & 0.13 & 0.01 & 0.50 & $(0.69-1.2)$ & -0.19 & -0.03 \\
\hline $\begin{array}{l}\text { Unmarried (includes } \\
\text { separated) }\end{array}$ & - & - & 1.0 & $(-)$ & - & - & 1.0 & $(-)$ & - & - \\
\hline Married & 0.15 & 0.03 & 0.9 & $(0.73-1.2)$ & -0.18 & -0.02 & 1.1 & $(0.90-1.4)$ & -0.16 & -0.02 \\
\hline Unemployed & - & - & 1.0 & $(-)$ & - & - & 1.0 & $(-)$ & - & - \\
\hline $\begin{array}{l}\text { Employed (part- or full- } \\
\text { time) }\end{array}$ & $1.4^{* \star \star}$ & 0.27 & $0.44^{\star \star \star}$ & $(0.35-0.56)$ & $-1.6^{\star}$ & -0.12 & $0.56^{\star \star \star}$ & $(0.43-0.71)$ & $-0.34^{* \star \star}$ & -0.33 \\
\hline Age & 0.02 & 0.01 & $0.98^{* \star *}$ & $(0.97-0.99)$ & -0.01 & $-0.06^{* \star}$ & $0.12^{\star *}$ & $(0.97-0.99)$ & -0.03 & -0.09 \\
\hline Education & -0.03 & -0.01 & $1.2^{\star \star \star}$ & $(1.1-1.3)$ & -0.03 & $-0.56^{\star}$ & -0.11 & $(0.91-1.1)$ & $-0.62^{\star \star}$ & -0.15 \\
\hline Income & 0.09 & 0.03 & 1.0 & $(0.85-1.1)$ & 0.02 & 0.01 & 0.97 & $(0.91-1.0)$ & 0.01 & 0.01 \\
\hline$\alpha$ & 6.8 & & 1.1 & & 4.5 & & 0.44 & & 8.0 & \\
\hline$R^{2}$ & 0.13 & & $0.18^{a}$ & & 0.13 & & $0.13^{\mathrm{a}}$ & & 0.18 & \\
\hline
\end{tabular}

${ }^{\star} P<0.05 ;{ }^{* \star} P<0.01 ;{ }^{* \star} P<0.001$ (two-tailed).

${ }^{a}$ Nagelkerke's $\mathrm{R}^{2}$.

pletely unhealthy adults reported a "lost" (ie, missed the entire day) workday compared with just more than $14 \%$ of adults with incomplete health and only $8 \%$ of adults with complete health. Even among adults who had any lost workdays, completely unhealthy adults missed an average of 9 days of work, while adults with incomplete health missed an average of 5.6 days, and completely healthy adults who had missed any days did so an average of only 4 days.

The multivariate analyses of the work-related productivity measures in Table 2 substantiate the descriptive findings. Even after adjustment for basic background characteristics, adults with incomplete health reported an average of a half point less work effort, and completely unhealthy adults report just over one point less work effort, than completely healthy adults. Completely unhealthy adults were over eight times and adults with incomplete health were over two times more likely to have any work cutbacks than adults with complete health. Among those with any cutbacks, completely unhealthy adults reported more than four more than complete healthy, whereas the difference in average cutback days between adults with incomplete and complete health did not approach statistical significance. Similarly, completely unhealthy adults were six times and adults with incomplete health were two times more likely to have any lost days of work than adults with complete health. Among those with any lost days of work, completely unhealthy adults reported just over 2 more missed days than complete healthy, whereas the difference in average lost workdays between adults with incomplete and complete health did not approach statistical significance.

Table 3 presents the unadjusted associations of measures of health care costs inputs with the complete health categories. Again, as predicted, completely healthy adults had lower levels of health care costs than adults with incomplete health, who in turn reported less health care costs inputs than completely unhealthy adults, who had markedly low levels of work performance. For instance, just more than one third of completely healthy adults had a work injury, compared with nearly onehalf of adults with incomplete health and nearly 6 of every 10 completely unhealthy adults. Although about $4 \%$ of completely healthy adults reported any hospitalization, nearly $12 \%$ of adults with incomplete health, and nearly $18 \%$ of completely unhealthy adults reported hospitalization. Moreover, the number of outpatient medical visits for physical and for mental health reasons was dramatically higher among completely unhealthy adults than adults with incomplete health. However, medical visits, especially for physical health reasons, were markedly higher among adults with incomplete health compared with completely healthy adults. Last, the prevalence of two 
TABLE 3

Unadjusted Association of Measures of Healthcare Cost Inputs With Complete Health (Sample Weighted)

\begin{tabular}{|c|c|c|c|c|}
\hline & $\begin{array}{l}\text { Completely Unhealthy } \\
n=567(18.8 \%)\end{array}$ & $\begin{array}{c}\text { Incomplete Health } \\
n=1878(62.2 \%)\end{array}$ & $\begin{array}{l}\text { Completely Healthy } \\
n=574(19.0 \%)\end{array}$ & $\begin{array}{c}\text { Mean or Total } \\
\%\end{array}$ \\
\hline Any work Injuries & $58.9 \%$ & $47.8 \%$ & $35.1 \%$ & $47.5 \%$ \\
\hline $\begin{array}{l}\text { Any overnight hospitalization } \\
\text { outpatient medical visits }\end{array}$ & $17.6 \%$ & $11.7 \%$ & $3.8 \%$ & $11.3 \%$ \\
\hline Mean physical health visits & 6.1 & 2.9 & 1.7 & 3.3 \\
\hline Mean mental health visits & 5.5 & 1.1 & 0.7 & 1.9 \\
\hline \multicolumn{5}{|l|}{ Prescription medications } \\
\hline Three or more medications & $24.5 \%$ & $13.9 \%$ & $1.9 \%$ & $13.6 \%$ \\
\hline
\end{tabular}

All $P$ values $<0.001$ (two-tailed).

\section{TABLE 4}

OLS and Simple Logistic Regressions of Healthcare Cost Inputs onto Complete Health Status (Sample Unweighted)

\begin{tabular}{|c|c|c|c|c|c|c|c|c|c|c|}
\hline \multirow[b]{2}{*}{ Predictor } & \multicolumn{2}{|c|}{ Any Work Injury } & \multicolumn{2}{|c|}{$\begin{array}{l}\text { Any Overnight } \\
\text { Hospitalization }\end{array}$} & \multicolumn{2}{|c|}{$\begin{array}{c}\text { Number } \\
\text { Medical Visits: } \\
\text { Physical }\end{array}$} & \multicolumn{2}{|c|}{$\begin{array}{c}\text { Number } \\
\text { Medical Visits: } \\
\text { Mental }\end{array}$} & \multicolumn{2}{|c|}{$\begin{array}{c}\text { Any } \\
\text { Prescriptions }\end{array}$} \\
\hline & OR & (95\% Cl) & OR & (95\% Cl) & b & $\boldsymbol{\beta}$ & b & $\boldsymbol{\beta}$ & OR & $(95 \% \mathrm{Cl})$ \\
\hline Completely healthy & 1.0 & $(-)$ & 1.0 & $(-)$ & - & - & - & - & 1.0 & $(-)$ \\
\hline Incomplete health & $1.6^{\star \star \star}$ & $(1.2-2.0)$ & $2.4^{\star \star \star}$ & $(1.6-3.7)$ & $1.0^{\star \star \star}$ & 0.09 & 0.38 & 0.02 & $2.6^{\star \star \star}$ & $(2.1-3.2$ \\
\hline Completely unhealthy & $2.1^{\star \star \star}$ & $(1.5-2.8)$ & $4.1^{\star \star *}$ & $(2.6-6.6)$ & $3.6^{\star \star \star}$ & 0.24 & $4.2^{\star \star \star}$ & 0.18 & $6.3^{\star \star \star}$ & $(4.8-8.3$ \\
\hline \multicolumn{11}{|l|}{ Control variables } \\
\hline Males & 1.0 & $(-)$ & 1.0 & $(-)$ & - & - & - & - & 1.0 & $(-)$ \\
\hline Females & $0.73^{\star \star \star}$ & $(0.61-0.87)$ & 1.1 & $(0.89-1.5)$ & $0.62^{\star \star}$ & 0.06 & 0.43 & 0.03 & $2.5^{\star \star \star}$ & $(2.1-2.9$ \\
\hline Non-Hispanic Whites & 1.0 & $(-)$ & 1.0 & $(-)$ & - & - & - & - & 1.0 & $(-)$ \\
\hline Minority Status & 0.97 & $(0.76-1.2)$ & 0.76 & $(0.55-1.0)$ & -0.25 & -0.03 & 0.22 & 0.02 & 0.94 & $(0.75-1.2$ \\
\hline $\begin{array}{l}\text { Unmarried (includes } \\
\text { Separated) }\end{array}$ & 1.0 & $(-)$ & 1.0 & $(-)$ & - & - & - & - & 1.0 & $(-)$ \\
\hline Married & 1.0 & $(0.85-1.3)$ & 0.84 & $(0.64-1.1)$ & -0.15 & -0.02 & $-1.7^{\star \star \star}$ & -0.09 & 0.96 & $(0.80-1.2$ \\
\hline Unemployed & 1.0 & $(-)$ & 1.0 & $(-)$ & - & - & - & - & 1.0 & $(-)$ \\
\hline $\begin{array}{l}\text { Employed (part- or full- } \\
\text { time) }\end{array}$ & $0.05^{\star \star \star}$ & $(0.04-0.06)$ & $0.49^{\star \star \star}$ & $(0.37-0.65)$ & $-0.92^{\star \star \star}$ & -0.07 & $-1.1^{\star \star}$ & -0.05 & 0.83 & $(0.68-1.0$ \\
\hline Age & 0.99 & $(0.99-1.0)$ & 0.99 & $(0.99-1.0)$ & -0.07 & -0.01 & 0.01 & 0.01 & $1.0^{\star \star \star}$ & $(0.99-1.1)$ \\
\hline Education & $0.79^{\star * *}$ & $(0.73-0.86)$ & 0.90 & $(0.81-1.0)$ & -0.02 & -0.01 & 0.10 & 0.03 & 1.0 & $(0.95-1.1)$ \\
\hline Income & $0.93^{\star \star}$ & $(0.89-0.98)$ & 0.89 & $(0.91-1.0)$ & 0.04 & 0.02 & $0.29^{\star \star}$ & 0.07 & 0.99 & $(0.94-1.1)$ \\
\hline$\alpha$ & 2.5 & & -0.45 & & 2.3 & & 1.6 & & -1.5 & \\
\hline $\mathrm{R}^{2}$ & $0.41^{a}$ & & $0.10^{a}$ & & 0.06 & & 0.04 & & $0.23^{a}$ & \\
\hline
\end{tabular}

${ }^{\star} P<0.05 ;{ }^{* \star} P<0.01 ;{ }^{* \star *} P<0.001$ (two-tailed).

a Nagelkerke's $\mathrm{R}^{2}$

prescription medications, or three or more medications, was dramatically higher among adults with complete ill-health than adults with incomplete health. Three quarters of completely healthy adults were not using any prescription medications, and largest proportion of completely healthy adults who were using prescription medication reported using only one medication.

The multivariate analyses of the regression of the health care costs measures in Table 4 corroborate the descriptive findings. Even after controlling for basic sociodemographic characteristics, completely unhealthy adults were two times, and adults with incomplete health were one and one-half times, more likely to have had any work injury than adults with complete health. Completely unhealthy adults were four times and adults with incomplete health were more than two times more likely than adults with complete health to have been hospitalized. Adults with incomplete health reported an average of one more medical visit, and completely unhealthy adults report more than three more medical visits for physical health than completely healthy adults. Completely unhealthy adults report more than four more medical visits for mental health than completely healthy adults; the difference in mental health medical visits between adults with incomplete and complete health was not statistically significant. Last, completely unhealthy adults were over six times more likely, and adults with incom- 
plete health were over two times more likely to report use of any prescription medications.

\section{Discussion}

The goal of this study was to determine whether there is added value of shifting the occupational health focus from viewing health as the absence of illness to health as a complete state or more than the absence of illness. The continued focus on health as the absence of diseases and disease risk factors has been met with increased years spent living and working unhealthy and with disability. ${ }^{32}$ We concur with David Cutler's ${ }^{44}$ view, stated in Your Money or Your Life, that "A population that lives long but is in poor health is not (much) better off that one with a shorter but healthier life span" (p. 5). The mission of every subdiscipline of public health to protect and improve health must begin to include the protection and promotion of complete health, which includes the presence of mental and physical well-being as well as the absence of physical and mental morbidity.

Health care in the 21st century, whether it provides clinical care or takes a population approach, should include an intensive effort to add healthy years to the added years of life expectancy. However, and despite established conceptions of health as more than the absence of disease, public health policy and evaluation of health programs are based primarily on reduction of mortality and morbidity, and their known behavioral risk factors such as smoking, physical activity, and diet. ${ }^{45}$ The exclusion from policy and research of health and wellbeing-which some consider the subjective counter-dimension of physical disease and mental disor$\mathrm{der}^{4,22}$ - may partially explain why the health profile of the US population, for example, is poor relative to other developed nations, and why some argue that the US suffers from an "epidemic of apprehension."46 Indeed, physical and psychiatric conditions frequently co-occur, and individuals without manifest signs of disease are not "healthy." 22 Policies that direct programmatic interventions that bring about reductions in illness and enhancements in mental and physical well-being are therefore necessary for reaching the $21 \mathrm{st}$ century health goals of 1) protecting health and 2) increase in healthy and disability-free life expectancy (ie, in addition to the extant goal of disease reduction).

Despite skepticism toward viewing health positively or as a complete state, a new empirical standard is needed to redirect and evaluate health programs and measure progress on population and occupational health. Complete health evenly balances the absence of individual morbidity and the presence of well-being. ${ }^{19}$ Conceptually, complete health takes seriously the World Health Organization's view of health as a biopsychosocial state that is more than the absence of disease or infirmity. It also views the absence of physical, psychological, and social illness and the presence of wellbeing within each of these domains as separate and equally important in the way individuals embody health.

A growing number of scholars from different disciplines are arguing that human health is a valuable form of human capital. Drawing on examples from around the world, such as the HIV/AIDS burden of SubSaharan Africa or advances in population health in East Asia, economists are questioning thelongstanding assumption that wealth causes health by arguing that health contributes to the creation of wealth. ${ }^{3}$ The fields of worksite health promotion and occupational health are moving beyond a health cost-containment model toward a model of productivity management and enhancement. ${ }^{17,47,48}$ Finally, although well-being or vitality are not specifically mentioned, organizational scholars argue that promoting positive psychological states among employees is an important strategy for organizations to obtain and maintain competitive advantage. ${ }^{49}$ These separate lines of research converge with our results to suggest that complete health is an important form of human capital that yields incremental benefits over the absence of disease.

The results of this study must be interpreted in light of two notable limitations. First, causal inferences cannot be made from our crosssectional data. Second, all of the measures used in this analysis were self-reported, increasing the possibility that a portion of the observed associations may be attributable to common-method variance. Future research can overcome these limitations by examining prospective associations between complete health and outcome variables of interest to researchers in specific organizational and community contexts. Additionally, it will be important to triangulate measurement on both the independent and dependent variable side of the equation to include objective and other measures (eg, proxy-reports) of illness, well-being, and outcomes.

Limitations notwithstanding, the present study strongly suggests that the health paradigm guiding health practice, including occupational health, should be expanded to include the study of complete health. As hypothesized, individuals with complete health reported placing greater thought and effort into work, missing fewer half days of work, and missing fewer whole days of work than all other adults. Moreover, individuals with complete health reported fewer work injuries, fewer medical visits, and fewer overnight hospitalizations, and less prescription medication usage than all other adults. Thus, there appears to be added value to promoting complete health, and justification for complementing health priorities for disease preven- 
tion with priorities for promoting health as a complete state.

\section{References}

1. Sigerist HE. Medicine and Human Welfare. New Haven, CT: Yale University Press; 1941.

2. Berger ML, Howell R, Nicholson S, Sharda C. Investing in healthy human capital. J Occup Environ Med. 2003;45: 1213-1225.

3. Bloom DE, Canning D. The health and wealth of nations. Science. 2000;287: 1207-1209.

4. Sullivan S. Making the business case for health and productivity management. J Occup Environ Med. 2004;46: $56-61$.

5. US Public Health Service. Surgeon General's virtual office. 2001 (online) Available at: www.surgeongeneral.gov; Internet; accessed 16 March 2005.

6. Bly JL, Jones RC, Richardson JE. Impact of worksite health promotion on health care costs and utilization. Evaluation of Johnson \& Johnson's Live for Life program. JAMA. 1986;256:32353240 .

7. Leviton LC. Can organizations benefit from worksite health promotion? Health Serv Res. 1989;24:159-189.

8. Aldana SG. Financial impact of health promotion programs: a comprehensive review of the literature. Am J Health Promot. 2001;15:296-320.

9. Serxner S, Gold D, Anderson D, Williams D. The impact of a worksite health promotion program on short-term disability usage. J Occup Environ Med. 2001; 43:25-29.

10. Serxner SA, Gold DB, Bultman KK. The impact of behavioral health risks on worker absenteeism. J Occup Environ Med. 2001;43:347-354.

11. Anderson DR, Whitmer RW, Goetzel $\mathrm{RZ}$, et al. The relationship between modifiable health risks and group-level health care expenditures. Health Enhancement Research Organization (HERO) Research Committee. Am J Health Promot. 2000; 15:45-52.

12. Danna K, Griffin RW. Health and wellbeing in the workplace: A review and synthesis of the literature. $J$ Manage. 1999;25:357-384.

13. McCunney RJ, Anstadt G, Burton WN, Gregg D. The competitive advantage of a healty work force: Opportunities for occupational medicine. J Occup Environ Med. 1997;39:611-613.

14. Pelletier KR. A review and analysis of the clinical and cost-effectiveness studies of comprehensive health pro- motion and disease management programs at the worksite: 1998-2000 update.

Am

J Health Promot. 2001;16:107-116.

15. Riedel JE, Lynch W, Baase C, Hymel $\mathrm{P}$, Peterson KW. The effect of disease prevention and health promotion on workplace productivity: a literature review. Am J Health Promot. 2001;15: 167-191.

16. Serxner SA, Gold DB, Grossmeier JJ, Anderson DR. The relationship between health promotion program participation and medical costs: a dose response. J Occup Environ Med. 2003;45:11961200.

17. McCunney RJ. Health and productivity: A role for occupational health professionals. J Occup Environ Med. 2001;43: 30-35.

18. World Health Organization. World Health Organization constitution. Geneva: World Health Organization; 1948.

19. Keyes CLM, Grzywacz JG. Complete health: prevalence and predictors among U.S. adults in 1995. Am J Health Promot. 17:131, 2002.

20. Lau RR. Cognitive representations of health and illness. In: Gochman DS, Ed. Handbook of Health Behavior Research: Personal and Social Determinants. New York: Plenum; 1997:1:51-70.

21. O'Donnell MP. Definition of health promotion: part III: expanding the definition. Am J Health Promot. 3:5, 1989.

22. Keyes CLM. The mental health continuum: from languishing to flourishing in life. J Health Soc Behav. 2002;43:207222.

23. Strümpfer DJW. The origins of health and strength: From 'salutogenesis' to 'fortigenesis.' S Afr J Psychol. 1995;25: 81-89.

24. Evans DL, Charney DS. Mood disorders and medical illness: a major public health problem. Biol Psychiatry. 2003;54:177180.

25. Mechanic D. Mental Health and Social Policy: The Emergence of Managed Care. Needham Heights, MA: Allyn \& Bacon; 1999.

26. Institute on Medicine, Health and Behavior. The Interplay of Biological, Behavioral, and Societal Influences. Washington, DC: National Academy Press; 2001.

27. Evans RG, Stoddart GL. Producing health, consuming healthcare. Soc Sci Med. 1990;31:1347-1363.

28. Young TK. Population Health: Concepts and Methods. New York: Oxford University Press; 1998.

29. Fries JF. Aging, natural death and the compression of morbidity. $N$ Engl J Med. 1980;303:130-135.

30. World Health Organization. Geneva: World Health Organization; 1978. Declaration of Alma-Ata International Conference on Primary Health Care. (online) Available from: www.who.int/hpr/NPH/ docs/declaration almaata.pdf; Internet; accessed 16 March 2005.

31. Labonte R, Schrecker RT. Committed to health for all? How the G7/G8 rate. Soc Sci Med. 2004;59:1661-1676.

32. Nusselder WJ, van der Velden K, von Sonsbeek JLA, Lenoir ME, van den Bos GAM. The elimination of selected chronic diseases in a population: the compression and expansion of morbidity. Am J Public Health. 1996;86:187-194.

33. World Health Organization. The World Health Report 2000 Health Systems: Improving Performance. Geneva: World Health Organization; 2000.

34. Lamm RD, Morreim EH. Health care: a Faustian bargain. Society. 2002;39: 33-38.

35. Olshansky SJ, Rudberg MA, Carnes BA, Cassell CK, Brody JA. Trading off longer life for worsening health. J Aging Health. 1991;3:194-216.

36. Grzywacz JG, Keyes CLM. Toward health promotion: physical and social behaviors in complete health. Am J Health Behav. 2004;28:99-111.

37. Breslow L. From disease prevention to health promotion. JAMA. 1999;281: 1030-1033.

38. Kish L, Frankel MR. Inference from complex samples. J R Stat Soc. 1974;36: $1-37$.

39. American Psychiatric Association. Diagnostic and Statistical Manual of Mental Disorders. 3rd (revised) ed. Washington, DC: American Psychiatric Association; 1987.

40. Kessler RC, Andrews G, Mroczek D, Ustun B, Wittchen HU. The World Health Organization Composite International Diagnostic Interview Short Form (CIDI-SF). Int J Methods Psychiatr Res. 1998;7:171-185.

41. Ryff CD. Happiness is everything, or is it? Explorations on the meaning of psychological well-being. J Pers Soc Psychol. 1989;57:1069-1081.

42. Ryff CD, Keyes CLM. The structure of psychological well-being revisted. J Pers Soc Psychol. 1995;69:719-727.

43. Keyes CLM. Social well-being. Soc Psychol Q. 1998;61:121-140.

44. Cutler DM; Your Money or Your Life: Strong Medicine for America's Health Care System. New York: Oxford University Press; 2004.

45. Robine JM, Ritchie K. Healthy life ex- 
pectancy: evaluation of global indicator of change in population health. BMJ. 1991;302:457-460.

46. Barsky AJ. The paradox of health. N Engl J Med. 1988;318:414-418.

47. Goetzel RZ, Ozminkowski RJ. Health and productivity management: Emerging opportunities for health promotion professionals for the 21 st century. Am $J$ Health Promot. 2000;14:211-214.

48. Kessler RC, Ames M, Hymel PA, et al. Using the World Health Organization Health and Work Performance Questionnaire (HPQ) to evaluate the indirect workplace costs of illness. J Occup Environ Med. 46:S23-S37, 2004.

49. Luthans F, Youssef CM. Human, social, and now positive psychological capital management: Investing in people for competitive advantage. Organ Dyn. 2004;33:143-160. 